\title{
Alzheimer's Disease: Differences of Transdermal versus Oral Treatment on Caregiving Time
}

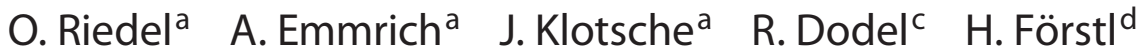 \\ W. Maier ${ }^{\mathrm{e}, \mathrm{f}}$ H. Reichmann ${ }^{\mathrm{b}}$ H.-U. Wittchen ${ }^{\mathrm{a}}$
}

a Institute of Clinical Psychology and Psychotherapy, Technische Universität Dresden, ${ }^{b}$ Department of Neurology, Faculty of Medicine Carl-Gustav Carus, Dresden, ' Department of Neurology, Philipps-University Marburg, ${ }^{\mathrm{d}}$ Department of Psychiatry and Psychotherapy, Technical University of Munich, e Department of Psychiatry and Psychotherapy, FriedrichWilhelms-University Bonn, and ${ }^{\mathrm{f}} \mathrm{German}$ Center for Neurodegenerative Diseases (DZNE), Bonn, Germany

\section{Key Words}

Dementia $\cdot$ Care $\cdot$ Caregiver $\cdot$ Burden $\cdot$ Rivastigmine $\cdot$ Patch

\begin{abstract}
Background: Data on indirect effects of dementia treatment on caregiver burden obtained from naturalistic studies are still lacking. We explored differences between patients with oral and transdermal application of acetylcholine esterase inhibitors regarding caregiver's time burden and psychopathology. Methods: A cross-sectional naturalistic cohort study of 403 patients in outpatient care with three treatment groups (none, oral, and transdermal) was conducted. Assessments included a standardized clinical burden questionnaire and a standardized caregiver interview. Results: Any treatment was associated with lower burden in most measures. Transdermal treatment was superior regarding (1) administration time $(p<0.001)$; (2) rates of administration problems ( $p=0.031)$; (3) burden in activities of daily living $(p=0.008)$, and (4) caregiver anxiety (OR $0.25 ; 95 \% \mathrm{Cl} 0.05-0.99)$. Caregivers did not report better quality of life regarding mental/physical health. Physicians' and caregivers' ratings of patients' improvements were not associated ( $\kappa=0.01-0.06$ ). Conclusions: Benefits associated with transdermal treatment do not translate into a better 'generic quality of life' of the caregiver. The substantially different perceptions of patients' improvements need to be considered in future studies.
\end{abstract}




\section{Introduction}

Acetylcholine esterase inhibitors and memantine are state-of-the-art interventions in Alzheimer's disease (AD). Their effect on cognitive functions, activities of daily living (ADL), and other patient-related outcomes has previously been documented in randomized placebo-controlled clinical trials [1-5]. Indirect effects of patient treatment on the caregiver are less well established and largely restricted to measures of quality of life, revealing moderate to no significant changes [6-8]. More detailed assessments of how the treatment changes the caregivers' overall time burden, related to treatment mode and effects on caregivers, are needed. While Wimo et al. [9] reported less caregiver time for moderate to severe $\mathrm{AD}$ patients treated with memantine, analogue data for acetylcholine esterase inhibitor treatment from drug studies are, to our knowledge, not available so far. This contrasts with the growing number of studies that have documented the adverse impact of home-based care of patients with AD on their caregivers. Recently, for rivastigmine, a transdermal formulation ('patch') has been introduced [10]. Potential advantages were shown, such as improved drug delivery due to different pharmacokinetic features, and better tolerability [11-13]. The claim of ease of administration is particularly interesting regarding the caregiver burden. The easier application could be associated with a reduced expenditure of time and fewer administration problems, both measurably affecting the overall burden of care.

Winblad et al. $[14,15]$ compared the efficacy and tolerability of the patch application versus capsules and placebos based on data from a large double-blinded randomized controlled trial on $>1,100$ patients with AD. Regarding the primary cognition outcomes, they demonstrated a similar efficacy of the patch compared to capsules, with superior tolerability in the former. Moreover, the vast majority (70\%) of caregivers preferred the patch treatment as it was easier to use and interfered less with their daily life [16, 17]. Efficacy and tolerability have also been recently confirmed in a post hoc analysis of AD patients who were concomitantly treated with memantine [18]. However, for the endpoint 'quality of life of the caregiver', a comparison of the transdermal versus the oral application of rivastigmine revealed no significant difference. To summarize the randomized clinical study data, so far, there is little evidence that treatment-related improvements of patients in cognitive and ADL measures also translate into significant benefits for the caregivers. Neither the oral nor the transdermal application data provide evidence of improved caregiver burden. It remains unclear whether this is due to the instruments chosen as endpoints for caregivers that might have failed to pick up relevant domains, or due to the more general issue that patients' improvements are relatively subtle and thus difficult to be recognized by the caregiver.

In the IDEA (Improving Alzheimer Dementia Treatment: Epidemiological Assessment of Doctors', Patients' and Caregivers' Unmet Needs) study, subsamples of patients with mild to moderate $\mathrm{AD}$ receiving their drugs in different ways (oral vs. patch) were naturalistically investigated. Additionally, a control group without drug treatment for dementia was incorporated as a reference. The primary aim of this paper is to describe differences between these subsamples regarding (1) caregiver's time burden; (2) frequencies of medication-associated problems of administration, and (3) to compare patients' improvements as perceived by the treating physicians and the caregivers. Moreover, we explored whether there were differences between caregivers with regard to their quality of life and frequencies of mental health problems. 
Table 1. Caregiver characteristics

\begin{tabular}{|c|c|c|c|c|c|c|c|}
\hline \multirow[t]{3}{*}{ Caregiver variables } & \multirow{3}{*}{$\begin{array}{l}\text { Total } \\
(\mathrm{n}=403)\end{array}$} & \multicolumn{6}{|c|}{ Treatment status of patient } \\
\hline & & \multicolumn{2}{|c|}{ A, none $(\mathrm{n}=62)$} & \multicolumn{2}{|c|}{$\mathrm{B}$, oral $(\mathrm{n}=280)$} & \multicolumn{2}{|c|}{ C, transdermal $(\mathrm{n}=61$} \\
\hline & & $\mathrm{n}$ & $\% \mathrm{w}$ & $\mathrm{n}$ & $\% \mathrm{w}$ & $\mathrm{n}$ & $\% \mathrm{w}$ \\
\hline \multicolumn{8}{|l|}{ Gender } \\
\hline Male & $124(30.8)$ & 19 & 30.7 & 91 & 32.5 & 14 & 23.0 \\
\hline Female & $279(69.2)$ & 43 & 69.4 & 189 & 67.5 & 47 & 77.1 \\
\hline \multicolumn{8}{|c|}{ Relationship to patient } \\
\hline Spouse & $195(48.5)$ & 20 & 32.3 & 141 & 50.5 & 34 & 55.7 \\
\hline Child & $146(36.3)$ & 30 & 48.4 & 96 & 34.4 & 20 & 32.8 \\
\hline Other & $61(15.2)$ & 12 & 19.4 & 42 & 15.1 & 7 & 11.1 \\
\hline \multicolumn{8}{|l|}{ Age groups } \\
\hline$\leq 55$ years & $130(32.6)$ & 22 & 35.5 & 90 & 32.5 & 18 & 30.0 \\
\hline $56-70$ years & $137(34.3)$ & 28 & 45.2 & 92 & 33.2 & 17 & 28.3 \\
\hline$\geq 71$ years & $132(33.1)$ & 12 & 19.4 & 95 & 34.3 & 25 & 41.7 \\
\hline Age, years & $62.1 \pm 13.6$ & \multicolumn{2}{|c|}{$60.0 \pm 12.5$} & \multicolumn{2}{|c|}{$62.2 \pm 14.0$} & \multicolumn{2}{|c|}{$63.9 \pm 12.8$} \\
\hline \multicolumn{8}{|l|}{ Living with patient } \\
\hline No & $143(36.4)$ & 37 & 60.7 & 94 & 34.4 & 12 & 20.3 \\
\hline Yes & $250(63.6)$ & 24 & $39.3^{1}$ & 179 & $65.6^{1}$ & 47 & $79.7^{1}$ \\
\hline \multicolumn{8}{|l|}{ Frequency of contact } \\
\hline Daily & $298(76.0)$ & 34 & $57.6^{2}$ & 212 & $77.4^{2}$ & 52 & $88.1^{2}$ \\
\hline Almost daily & $65(16.6)$ & 15 & 25.4 & 47 & 17.2 & 3 & 5.1 \\
\hline Less frequent & $29(7.4)$ & 10 & 17.0 & 15 & 5.5 & 4 & 6.8 \\
\hline \multicolumn{8}{|c|}{ Duration of caregiving } \\
\hline months & $40.1 \pm 33.3$ & 48. & 42.8 & 40.1 & & 31. & \\
\hline
\end{tabular}

Values in the first column are means $8 \mathrm{SD}$ or numbers with percentages in parentheses. Total-sample unweighted significant between-group differences are printed in bold. \%w $=$ unweighted.

${ }^{1}$ A vs. B: OR 2.94 (95\% CI 1.66-5.19), $\mathrm{p}=0.001$; A vs. C: OR 6.04 (95\% CI 2.67-13.65), $\mathrm{p}=0.001$; $\mathrm{C}$ vs. B: OR 2.06 (95\% CI 1.04-4.07), $\mathrm{p}=0.038$.

${ }^{2}$ A vs. B: OR 0.38 (95\% CI 0.21-0.68), $\mathrm{p}=0.001$; A vs. C: OR 0.19 (95\% CI 0.07-0.47), $\mathrm{p}=0.001$.

${ }^{3} \mathrm{C}$ vs. A: difference -17.0 (95\% CI -30.0 to -3.9$)$, $\mathrm{p}=0.011$.

\section{Methods}

The IDEA study was a cross-sectional naturalistic study of originally 1,366 eligible office-based neurologists in Germany that examined the caregiver burden in patients with AD. Eligible study physicians had to be office-based neurologists, had to treat patients with AD on a regular basis, and had to be available during the study period (2010). The present analysis is based on a subset of 97 participating physicians with a total of $403 \mathrm{AD}$ patients and their caregivers enrolled so far in the IDEA study.

Inclusion and exclusion criteria for patients and caregivers were kept as minimal as possible to reflect the situation in daily routine care. Eligible study patients had to have a clinically confirmed ICD-10 diagnosis of mild or moderate possible/probable AD [19] and a current caregiver providing daily informal care to the patient. Eligible caregivers had to accompany the patient to the visit and to agree to participate. Cohabitation was not mandatory, although it applied to the majority of caregivers (table 1). Consistent with the study protocol and informed consent procedure (approved by the local ethics committee, No. EK 75032009, July 4, 2009), both patient and caregiver had to give written informed consent. In case of a patient's inability to consent due to progressed dementia, his/her legal representative was asked to do so. 
To obtain higher statistical power and to minimize potential differences between the three treatment groups (oral, transdermal, and none), patients were matched by the study center using propensity score matching (see Statistics for further details). For clarity, the 'raw' data of the patients and their caregivers will be described first in the Methods after presenting the assessment material. Data from the matched sample will be shown in the Results.

\section{Study Material and Instruments}

For each patient, three data sources were available: (1) a standardized clinical assessment by the treating physician; (2) a questionnaire completed by the caregiver, and (3) a subsequent standardized computer-assisted telephone interview with the caregiver. It took approximately 50-70 min and focused on a more comprehensive description of the care situation as well as the caregiver's own physical and mental health status.

Patient's Clinical and Treatment Status

In addition to sociodemographic data from the patient, clinical information was obtained from the standardized clinical assessment. The physician documented age of AD onset, severity, and the current score on the MMSE [20]. Further data on concomitant mental and somatic diseases according to broad ICD classes were coded. Neuropsychiatric symptoms were rated by the physician on a symptom list according to the Neuropsychiatric Inventory [21].

The physicians also listed the dementia treatment status (current and past, if applicable), including agent, application form and duration, and reasons for regimen change. For the current treatment, they were asked to rate the improvement of cognitive functions, noncognitive symptoms, and functional ADL status of the patient on a four-point scale $(0=$ not at all, to 3 =good). Concomitant central nervous system medication was also recorded (antidepressants, neuroleptics, anxiolytics or others). Additionally, we used the physician-rated clinical global impression of improvement in memory/cognition, ADL, and behavioral problems.

Patient's Functional Status (ADL)

Information on the patient's impairment in ADL was obtained from the caregiver (questionnaire and subsequent comprehensive interview, as described above). The functional status of the patient was characterized by the use of the instrumental ADL scale [22] and the Barthel index score [23]. Similar to the clinical assessment conducted by the physician, improvement of memory/cognition, ADL, and behavioral problems of the patient was documented as perceived by the caregiver.

\section{Caregiver's Perceived Burden of Care}

Information on the caregiver's burden due to the care situation was obtained from the interview. The daily and weekly time burden in hours and minutes for five domains of care (participation in social activities, mobility, household/ADL, communication, and self-care) was documented. From these data, the following indicators were chosen for this paper: (1) total duration of care (in h/week); (2) duration of assisting in patient's self-care (h/week); (3) total time investment involved in applying the medication (min/week), and (4) number of times per week with problems in administering the AD medication. The caregiver's preference for treatment mode (marked preference, slight preference, or none) was evaluated with items from the AD Caregiver Preference Questionnaire (ADCPQ) [16]. These ratings were recorded with consideration of (1) the overall frequency and severity of patients' symptoms, as well as (2) the ease of administration. 
Moreover, Likert scale ratings regarding perceived overall caregiver burden were applied. The burden of special care was assessed with regard to the frequency of a need for the caregiver to stimulate for ADL, the frequency of supervision necessary to prevent the patient from running away, the supervision of self-harm, physically demanding care, and night time supervision. Each item could be coded (and scored) as 'daily' (5), ' $>1$ times per week' (3), 'once a week' (2), 'once in 2 weeks' (1) or 'never' (0). Mean and total scores were computed from these items.

Caregiver's Own Health Status and Psychopathology

The caregivers were asked to rate their own physical health with the EQ-5D VAS [24] and their mental health on an analogue scale (from 0 to 100, higher values indicate better condition). For the detection of depression and generalized anxiety disorders according to DSM-IV criteria, the Depression-Screening Questionnaire that also allows for the derivation of the diagnosis of major depression, as well as section items for generalized anxiety disorder and panic disorder from the Composite International Diagnostic Interview were used [2527].

\section{Patients (Raw Data)}

In the unselected sample of $403 \mathrm{AD}$ patients and caregivers, $69.5 \%$ of patients were currently treated with oral medication (hereof $81.4 \%$ with acetylcholine esterase inhibitors and $18.6 \%$ with memantine), $17.1 \%$ were treated with patches, and $15.4 \%$ did not receive any dementia drug (table 2).

Treatment duration was 20.5 months (mean) for oral and 17.0 months for transdermal medication ( $\mathrm{p}=0.587$; table 2 ). Among patients with oral treatment, $30.3 \%$ had been treated for $0-6$ months, $25.1 \%$ for $7-12$ months, $17.7 \%$ for $13-24$ months, and $26.9 \%$ for $>24$ months. Among patients with patch treatment, these proportions were $22.7 \%$ (0-6 months), $31.8 \%$ (7-12 months), $25.0 \%$ (13-24 months), and 20.5\% (>24 months).

Mean age of AD patients was $77.6 \pm 7.6$ years with a mean disease duration of $36.7 \pm$ 32.9 months. Independent of treatment status, patients had a high rate of comorbidities, with $>80 \%$ of all patients suffering from additional medical conditions, such as cardiovascular diseases (21.1\%) or diabetes (13.9\%). 32.3\% of patients had $>3$ additional conditions (data not shown). Additional central nervous system medication was prescribed for $43.2 \%$ of all patients (most frequently neuroleptics: $17.6 \%$; rarely antidepressants: $3.7 \%$ ). Patients in the oral and transdermal group had a significantly lower prior duration of AD (oral: 36.6 months; transdermal: 27.0 months; $\mathrm{p}=0.038$ ) compared to the untreated patients (duration: 51.1 months; $\mathrm{p}=0.007$ ). Further, Barthel scores were significantly worse in the untreated group (64.4) as compared to both treated groups $(\mathrm{p}=0.008$ and $\mathrm{p}=0.039)$ and somatic morbidity was higher in the treated groups (untreated: $67.7 \%$; treated: 81.1 and $88.5 \% ; p=0.022$ ). The three groups did not differ in their scores on the MMSE ( $\mathrm{p}=0.347)$, nor on any other variable reported.

\section{Caregivers (Raw Data)}

Table 1 displays the characteristics of the corresponding caregivers in total and stratified to the patients' dementia treatment. The caregivers were predominantly female (69.2\%) with a mean age of $62.1 \pm 13.6$ years, and $33.1 \%$ of caregivers were older than 71 years.

Caregivers were mostly spouses $(48.5 \%)$ or adult children $(36.3 \%)$, while $15.2 \%$ of caregivers were others (e.g. sons-in-law/daughters-in-law, grandchildren, or friends/neighbors). The majority cohabited with the patient $(63.6 \%)$ and was in contact with to him/her on a daily basis (76\%). The mean duration of caregiving was $40.1 \pm 33.3$ months, with the longest duration in untreated patients (mean: 48.6 months) and the shortest in transdermally treat- 
Riedel et al.: Alzheimer's Disease: Differences of Transdermal versus Oral Treatment on

Caregiving Time

Table 2. Biosocial and clinical characteristics of patients by comparison groups

\begin{tabular}{|c|c|c|c|c|}
\hline \multirow[t]{2}{*}{ Patient variables } & \multirow{2}{*}{$\begin{array}{l}\text { Total } \\
(n=403)\end{array}$} & \multicolumn{3}{|l|}{ Treatment } \\
\hline & & $\begin{array}{l}\text { A, none } \\
(\mathrm{n}=62)\end{array}$ & $\begin{array}{l}\text { B, oral } \\
(n=280)\end{array}$ & $\begin{array}{l}\mathrm{C} \text {, transdermal } \\
(\mathrm{n}=61)\end{array}$ \\
\hline \multicolumn{5}{|l|}{ Sociodemographics } \\
\hline \multicolumn{5}{|l|}{ Gender } \\
\hline Male & 38.7 & 25.8 & 39.3 & 49.2 \\
\hline Female & 61.3 & $74.2^{1}$ & $60.7^{1}$ & $50.8^{1}$ \\
\hline Age, years & $77.6 \pm 7.6$ & $78.8 \pm 7.5$ & $77.6 \pm 7.5$ & $76.3 \pm 8.2$ \\
\hline \multicolumn{5}{|l|}{ Marital status } \\
\hline Not married & 2.6 & 8.3 & 1.8 & 1.7 \\
\hline Married & 58.3 & 45.8 & 58.5 & 67.8 \\
\hline Divorced & 1.6 & 0.0 & 2.2 & 0.0 \\
\hline Widowed & 37.5 & 45.8 & 37.5 & 30.5 \\
\hline Education, years & $8.8 \pm 2.1$ & $8.7 \pm 1.3$ & $8.8 \pm 2.2$ & $8.8 \pm 2.2$ \\
\hline \multicolumn{5}{|l|}{ Highest educational degree } \\
\hline None & 3.1 & 2.4 & 2.7 & 5.5 \\
\hline Secondary school & 75.1 & 65.9 & 77.8 & 69.1 \\
\hline Middle school & 14.0 & 24.4 & 11.5 & 18.2 \\
\hline High school/university & 7.8 & 7.3 & 8.0 & 7.2 \\
\hline \multicolumn{5}{|l|}{ Dementia status } \\
\hline MMSE score & $17.8 \pm 5.6$ & $17.0 \pm 6.4$ & $17.7 \pm 5.7$ & $19.0 \pm 4.3$ \\
\hline \multicolumn{5}{|l|}{ Severity of $\mathrm{AD}$} \\
\hline Mild & 34.4 & 36.1 & 33.1 & 39.3 \\
\hline Moderate & 65.6 & 63.9 & 66.9 & 60.7 \\
\hline Duration of $\mathrm{AD}$, months & $36.7 \pm 32.9$ & $51.1 \pm 51.1^{2}$ & $36.6 \pm 30.4^{2}$ & $27.0 \pm 22.6^{2}$ \\
\hline Duration of current treatment, months & $19.8 \pm 23.1$ & - & $20.5 \pm 24.6$ & $17.0 \pm 16.0$ \\
\hline ADL (Barthel index score) & $73.1 \pm 25.5$ & $64.4 \pm 28.6^{3}$ & $74.6 \pm 24.9^{3}$ & $74.4 \pm 23.9^{3}$ \\
\hline Instrumental ADL & $2.3 \pm 2.3$ & $2.2 \pm 2.4$ & $2.4 \pm 2.4$ & $1.9 \pm 1.8$ \\
\hline \multicolumn{5}{|l|}{ General health status } \\
\hline Body mass index & $25.8 \pm 4.0$ & $26.8 \pm 5.2$ & $25.7 \pm 3.8$ & $25.8 \pm 3.7$ \\
\hline \multicolumn{5}{|l|}{ General somatic condition } \\
\hline Good & 63.8 & 53.1 & 65.3 & 65.5 \\
\hline Moderate & 27.0 & 34.7 & 25.2 & 29.3 \\
\hline Bad & 9.2 & 12.2 & 9.5 & 5.2 \\
\hline \multicolumn{5}{|l|}{ Nutritional condition } \\
\hline Undernourished/cachectic & 10.6 & 17.0 & 9.9 & 8.5 \\
\hline Normal & 69.9 & 57.5 & 71.4 & 72.9 \\
\hline Overweight & 15.8 & 19.2 & 16.1 & 11.9 \\
\hline Obese & 3.7 & 6.4 & 2.6 & 6.8 \\
\hline Any somatic comorbidities & 80.2 & $67.7^{4}$ & $81.1^{4}$ & $88.5^{4}$ \\
\hline \multicolumn{5}{|l|}{ Somatic comorbidities } \\
\hline None & 19.8 & 32.3 & 18.9 & 11.5 \\
\hline $1-2$ & 47.9 & 33.9 & 51.4 & 45.9 \\
\hline$>3$ & 32.3 & 33.9 & 29.6 & 42.6 \\
\hline
\end{tabular}

Values are means \pm SD or percentages. Total-sample unweighted significant between-group differences are printed in bold. For better legibility, columns containing the $n$ values have been deleted from this table. They are available on request.

${ }^{1}$ A vs. B: OR 0.53 (95\% CI 0.29-0.99), p = 0.049; A vs. C: OR 0.40 (95\% CI 0.17-0.77), p = 0.008.

2 B vs. A: difference -14.5 (95\% CI -24.9 to -4.0$), \mathrm{p}=0.007$; C vs. A: difference -24.1 (95\% CI -36.8

to -11.3$), \mathrm{p}=0.001$; $\mathrm{C}$ vs. B: difference $-9.6(95 \% \mathrm{CI}-18.7$ to -0.5$), \mathrm{p}=0.038$.

${ }^{3}$ A vs. B: difference 10.2 (95\% CI 2.6-17.8), $\mathrm{p}=0.008$; A vs. C: difference 9.9 (95\% CI 0.5-19.4), $\mathrm{p}=0.039$.

${ }^{4}$ B vs. A: OR 2.04 (95\% CI 1.11-3.76), $\mathrm{p}=0.022$; C vs. A: OR 3.67 (95\% CI 1.42-9.50), $\mathrm{p}=0.007$. 
ed patients (mean: 31.7 months). Caregivers of transdermally (79.7\%) and orally treated patients $(65.6 \%)$ lived more frequently together with the patient in the same household as compared to untreated patients (39.3\%; $\mathrm{p}<0.001 \mathrm{each}$ ), and they had more frequently daily contact (oral: $77.4 \%$; transdermal: $88.1 \%$ ) as compared to the untreated patients $(57.6 \% ; \mathrm{p}<0.001$ each). However, the total duration of caregiving was largest in the untreated and lowest in the transdermal group (48.6 vs. 40.1 vs. 31.7 months; $\mathrm{p}=0.011$ ).

\section{Design and Comparison Groups}

Because of the between-group differences described above, a matched control group design with three comparison groups was applied using propensity score matching with full Mahalanobis matching. These methods adjust for observed differences between the groups and make the groups comparable in respect to the matched characteristics. Matching characteristics were gender, age, and severity and duration of AD. Accounting for the differences in patients' characteristics and sample sizes, we matched the groups regarding the observed differences and applied statistical weights to account for the differences in sample size. The following three comparison groups were defined: group A: no drug treatment $(n=61)$; group B: oral treatment $(n=61)$, and group B: transdermal treatment $(n=$ $61)$.

\section{Statistics}

Linear regression analyses were conducted to estimate differences in continuously distributed variables between the groups. We estimated associations with categorical predictor variables as odds ratios (OR) with $95 \%$ confidence intervals (CI) by using logistic regression models. Statistical inference was based on a significance level of 5\%. Standard errors and CIs were calculated by the Huber-White sandwich estimator to take the clustered sampling design into account [28]. We conducted individual statistical tests for individual hypotheses. As we did not aim to test a global hypothesis, we did not correct the p value level for multiple testing purposes. The sample size of 61 for each comparison group yielded a statistical power above $80 \%$ for a hypothesized medium effect size $>0.5$.

\section{Results}

\section{Group Differences in Time Burden and Perceived Preferences}

Figure 1 shows a lower time burden for caregivers of patients with transdermal treatment as compared to the oral administration (37.2 vs. $70.5 \mathrm{~min} ; \mathrm{p}<0.001)$. Also, in this group, the mean number of problems/week in administering the medication was lower as compared to the oral group ( 0.7 vs. 1.2 times; $p=0.031$ ). No problems were reported by $27.9 \%$ of caregivers in the transdermal group ( $21.3 \%$ in the oral group). No differences were observed regarding the additional use of nursing services (oral group: $23.0 \%$; transdermal group: $21.0 \%$ ); however, both groups had significantly lower values than the untreated control group $(52.5 \%$; A vs. $B: p=0.485$; A vs. $C: p=0.134 ; B$ vs. $C: p=0.383$ ).

In all groups, the mean time of caregiving exceeded $43 \mathrm{~h}$ (range $0-133$ ), with no significant between-group differences (data not shown). The time expenditure for direct assistance in basic self-care was $8.5 \pm 9.0 \mathrm{~h} /$ week in the oral and $8.2 \pm 9.8 \mathrm{~h} /$ week in the transdermal group. Untreated cases revealed a slightly higher mean of $9.0 \pm 9.2 \mathrm{~h} /$ week ( $\mathrm{p}$ value not significant).

Twelve caregivers had previous experience with the oral medication before the patch was applied. Hereof, $50 \%$ preferred the patch in terms of ease of use, while $33 \%$ preferred oral medication ( $16.7 \%$ were undecided). 


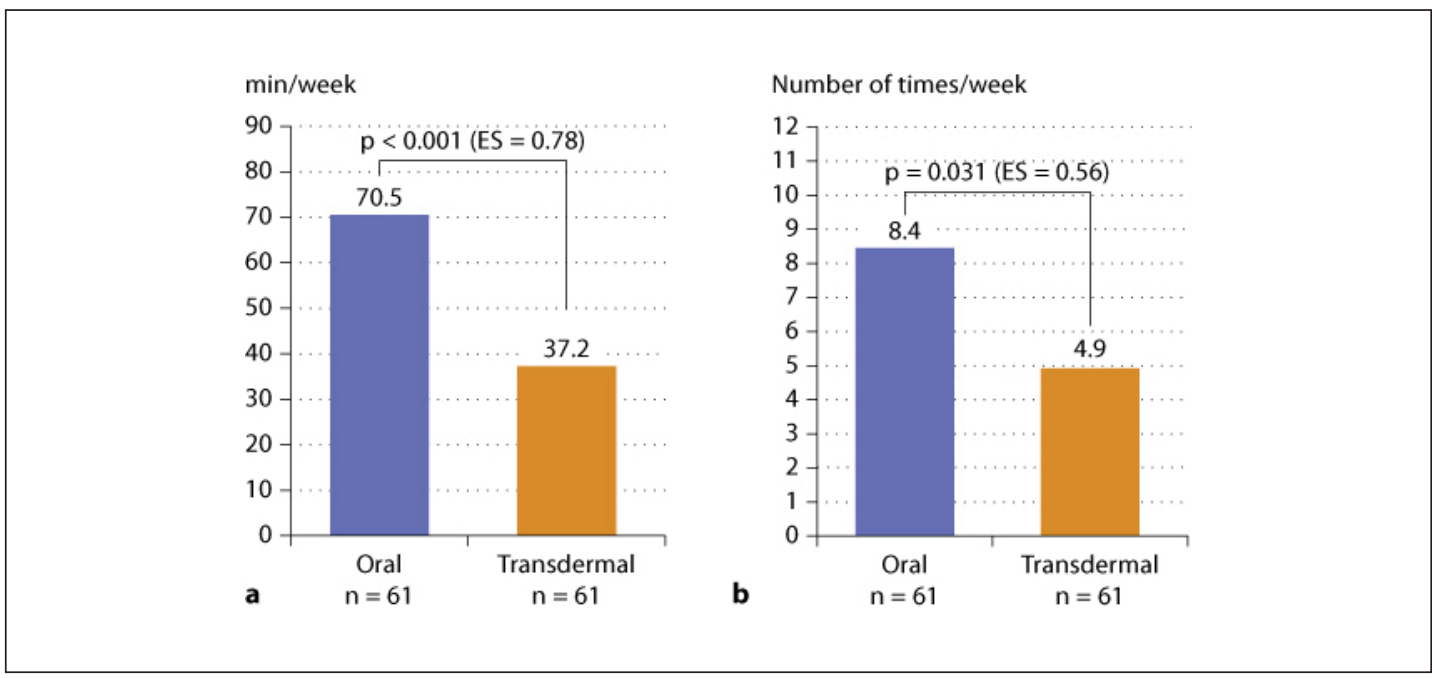

Fig. 1. Time needed for drug administration (a) and number of times of administration problems (b) experienced by caregivers in orally and transdermally treated patients. ES $=$ Effect size.

\section{Group Differences in Caregivers' Health and Perceived Burden}

Compared with caregivers of untreated patients, caregivers of patients in both treatment groups revealed a significantly lower perceived total burden of care (B vs. A and C vs. A: p < 0.001 each). We also tested whether duration of treatment had an effect on caregivers' perceived overall burden by the use of a logistic regression model (data not shown). We neither found significant effects in the orally $(\mathrm{p}=0.549)$ nor in the transdermally treated group $(\mathrm{p}=0.920)$. Table 3 illustrates the domain scores of caregivers' burden with regard to five critical domains, expressed as the frequency per week in which the caregiver had to perform the respective activities. In the transdermal treatment group, caregivers rated their burden as significantly lower (Cohen effect size 0.51 ) with regard to ADL performed by patients without caregivers' involvement (mean: $2.75 ; \mathrm{p}=0.008$ ). The orally treated group had a significantly less mean of 3.61 than untreated patients (mean: 4.03; $\mathrm{p}<0.001$ ). All other functional domains (supervision of running away, self-harm, physically demanding care, and night time supervision) including the total score showed no significant between-group differences.

Inconsistent effects were observed for the psychopathological status of the caregivers of treated patients. The transdermal treatment group revealed slightly higher depression symptom scores in comparison to the oral treatment group (OR 1.93; 95\% CI 0.58-3.29) and a slightly higher proportion of major depression according to the Depression-Screening Questionnaire (25 vs. $21.9 \%$; OR 1.29; $95 \%$ CI $0.37-3.79$ ). However, they also had significantly lower rates for generalized anxiety disorder (OR 0.25 ; 95\% CI 0.05-0.99) and for panic syndromes (OR 0.47; 95\% CI 0.08-1.75).

\section{Dementia Treatment: Comparison of Efficacy Appraisal}

Figure 2 compares caregivers' and physicians' overall ratings of perceived effects of orally and transdermally treated patients with regard to three domains: memory and cognition, $\mathrm{ADL}$, and behavioral symptoms of AD. Among patients with oral dementia treatment (fig. 2a), caregivers reported more frequently improvements than physicians regarding the patients' behavior ( 90.1 vs. $67.8 \% ; \mathrm{p}=0.021$ ). In the transdermal treatment group (fig. $2 \mathrm{~b}$ ), 
Table 3. Caregivers' quality of life and psychopathological burden

\begin{tabular}{|c|c|c|c|c|}
\hline \multirow[t]{2}{*}{ Caregiver variables } & \multicolumn{3}{|c|}{ Dementia treatment status } & \multirow{2}{*}{$\begin{array}{l}C \text { versus B statistics; } \\
\text { ES }\end{array}$} \\
\hline & $\begin{array}{l}\text { A, none } \\
(\mathrm{n}=61)\end{array}$ & $\begin{array}{l}\text { B, oral } \\
(\mathrm{n}=61)\end{array}$ & $\begin{array}{l}\mathrm{C} \text {, transdermal } \\
(\mathrm{n}=61)\end{array}$ & \\
\hline \multicolumn{5}{|l|}{ Perceived burden of care } \\
\hline Perceived overall burden of care ${ }^{1}$ & $2.31 \pm 0.80$ & $1.57 \pm 0.69$ & $1.72 \pm 0.67$ & $\mathrm{p}=0.926 ; 0.22$ \\
\hline \multicolumn{5}{|c|}{ Perceived burden in caregiving domains ${ }^{2}$} \\
\hline Stimulation to ADL & $4.03 \pm 1.37$ & $3.61 \pm 1.48$ & $2.75 \pm 1.85$ & $p=0.008 ; 0.51$ \\
\hline Supervision of running away & $0.95 \pm 1.60$ & $0.98 \pm 1.72$ & $1.07 \pm 1.53$ & $\mathrm{p}=0.802 ; 0.05$ \\
\hline Supervision of self-harm & $2.15 \pm 2.06$ & $1.72 \pm 1.71$ & $1.92 \pm 1.81$ & $\mathrm{p}=0.604 ; 0.11$ \\
\hline Physically demanding care & $1.41 \pm 1.39$ & $1.26 \pm 1.62$ & $1.43 \pm 1.69$ & $\mathrm{p}=0.608 ; 0.10$ \\
\hline Night time supervision & $0.89 \pm 1.25$ & $0.79 \pm 1.25$ & $1.20 \pm 1.62$ & $\mathrm{p}=0.146 ; 0.28$ \\
\hline Total score & $9.43 \pm 4.15$ & $8.36 \pm 5.67$ & $8.36 \pm 5.18$ & $\mathrm{p}=1.00 ; 0.00$ \\
\hline \multicolumn{5}{|l|}{ Health status } \\
\hline Physical quality of life & $64.2 \pm 21.3$ & $63.4 \pm 19.3$ & $57.9 \pm 23.0$ & $p=0.206 ; 0.27$ \\
\hline Mental quality of life & $59.8 \pm 20.9$ & $55.5 \pm 20.6$ & $51.6 \pm 22.1$ & $\mathrm{p}=0.383 ; 0.18$ \\
\hline DSQ score s $^{3}$ & $4.24 \pm 3.17$ & $4.46 \pm 2.79$ & $6.39 \pm 4.07$ & $\mathrm{p}=0.006 ; 0.55$ \\
\hline Major depression & 13.9 & 21.9 & 25.0 & OR $1.29(0.37-3.79)$ \\
\hline Generalized anxiety disorder ${ }^{4}$ & 22.2 & 21.2 & 6.3 & OR $0.25(0.05-0.99)$ \\
\hline Panic syndrome & 12.8 & 12.5 & 6.3 & OR $0.47(0.08-2.75)$ \\
\hline
\end{tabular}

Values are means \pm SD or percentages. Bold values indicate significantly lower or higher values than in the comparison group(s). ES = Effect size; DSQ = Depression-Screening Questionnaire; $\mathrm{MD}=$ mean difference estimated by linear regression analyses; $\mathrm{OR}=$ odds ratio estimated by logistic regression analyses.

${ }^{1}$ Lower values indicate lower burden; A vs. B: MD -0.75 (95\% CI -1.04 to -0.46$)$; A vs. C: MD -0.59 (95\% CI -0.88 to -0.30$)$.

${ }^{2}$ Higher values indicate higher burden.

${ }^{3} \mathrm{C}$ vs. A: MD 2.15 (95\% CI 0.79-350), $\mathrm{p}=0.002$; result is also significant after adjustment for gender.

${ }^{4}$ C vs. A: OR 0.23 (95\% CI 0.05-0.96).

caregivers more frequently perceived improvements on all three domains as compared with physicians with significant differences for behavior ( $93.5 \mathrm{vs.} 64.1 \% ; \mathrm{p}=0.014$ ) and a trend for memory/cognition (83.9 vs. $60.8 \%$; $\mathrm{p}=0.086$ ).

When comparing the two treatment modes, caregivers more often reported the transdermal application to improve memory/cognition than the oral treatment (83.9 vs. $62.7 \%$; $\mathrm{p}<0.05)$, while physicians did not $(60.8 \mathrm{vs} .59 .8 \%$; $\mathrm{p}=0.574)$. This contrasts sharply with the treating physicians' ratings not showing any systematic difference between the two treatment modes and overall considerably lower improvement/stable ratings in the same domain. In fact, there is only a coincidental agreement between the caregiver and physician regarding the patient's improvement as reflected by a low percentage of agreement $(54.6 \mathrm{vs} .69 .1 \%)$ and low $\kappa$ values (range $0.01-0.06$ ).

\section{Discussion}

In this naturalistic cross-sectional matched control study, we found differences between transdermally and orally treated $\mathrm{AD}$ patients with regard to some more subtle measures that so far have not received considerable attention in the literature: a reduced time burden and lower problems in treatment-related activities of the caregiver, and improved ADL of the pa- 


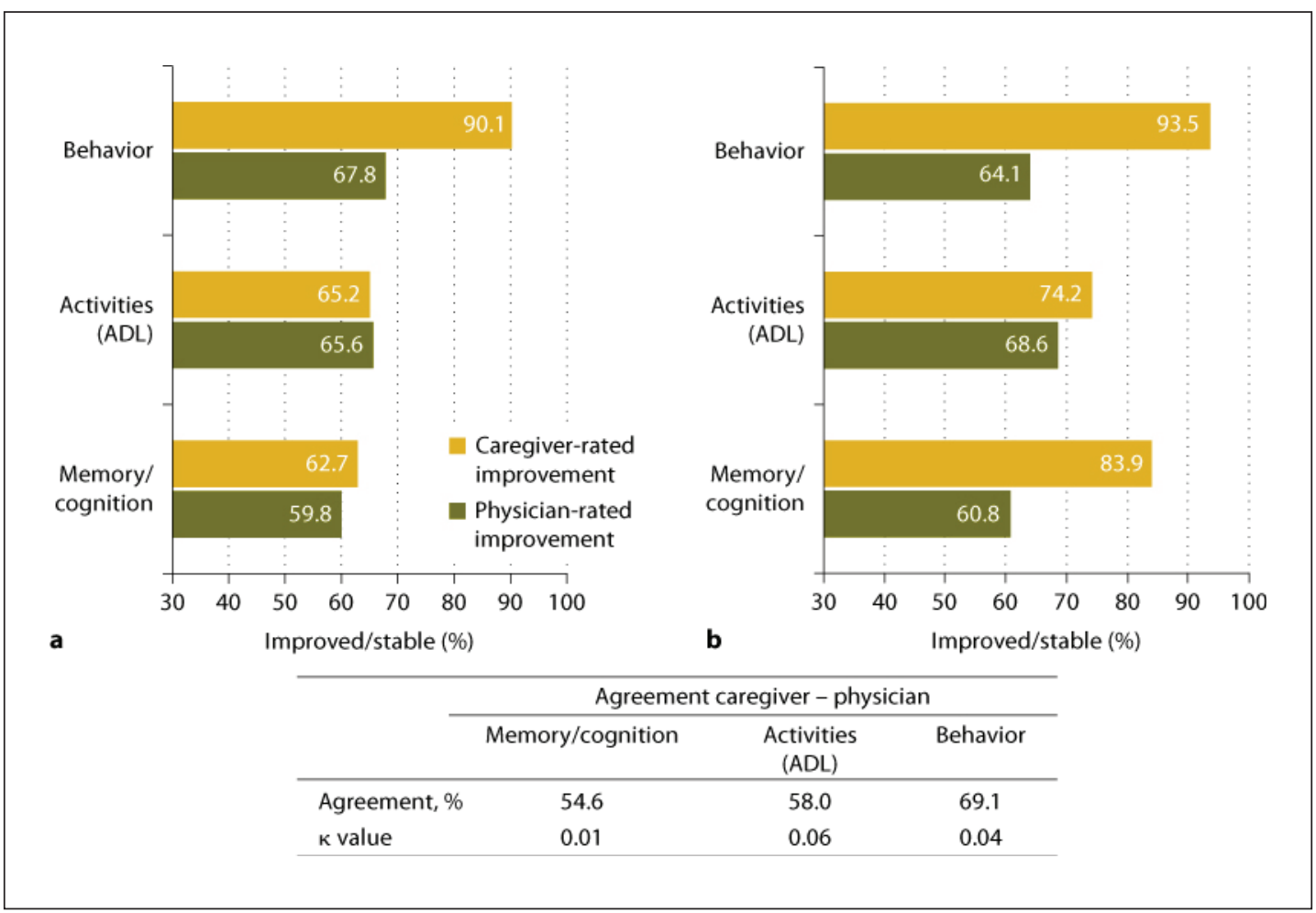

Fig. 2. Caregiver and treating physician-rated perceived improvements in patients treated with oral (a) or transdermal (b) dementia treatment.

tient. These correlates, however, seem not to translate into an overall significantly better quality of life of the caregiver, nor are there consistent differences with regard to various other functional domains or mental health of the caregiver in general.

Our study also revealed that studies aiming to measure effects of improved patient treatment on caregiver burden should carefully select how these effects are being assessed. We found large differences in rating patient improvements as well as caregiver burden depending on whether we used information from the caregiver or the treating physician. Obviously, substantially different perceptions and rating habits of physicians and caregivers exist that need to be considered more carefully in future studies. It is possible that caregivers, although mostly lacking a clinical education, are better sources than physicians when rating the patient's functional status in everyday familial life [29]. This is not surprising as patients with $\mathrm{AD}$ are usually scheduled quarterly for evaluation purposes, at least by the specialty care of office-based neurologists. Thus, the physicians might have little knowledge about the patient's everyday functional status at home or about problems of the caregiver.

Before commenting on these findings in more detail, the limitations of this study should be highlighted. This is a naturalistic cross-sectional study in routine care. The advantages are the most likely lack of substantial systematic selection effects, which are typical for highly selective and more controlled convenience samples. However, as the reverse of the medal, this study design also bears drawbacks. The fact that treatments were not randomized and were allocated prior to the study by unknown criteria of the treating physician prohibits any causal statements about the benefits of oral and transdermal treatments. As we lack 'real' pre- and post-drug administration assessment, we cannot infer for sure whether the differ- 
ences found are really due to the form of drug administration or rather due to differences in other variables prior to administration. Moreover, due to the study design as mentioned above, we also lack data on the appropriateness of drug treatment or the adequacy of dosage. Further limitations are: the cross-sectional study design not allowing to measure changes, the low sample size and reduced statistical power, differences between groups that were only partially controlled for, and patient treatment effects although assessed were not considered in this present paper. It should also be noted that data obtained from naturalistic studies can be more heterogeneous than data obtained from randomized controlled trials, leading to higher biases. We tried, however, to minimize potential biases by optimally matching the patient and caregiver groups as previously described.

With these limitations in mind, we confirm overall that both transdermal and oral treatment seems to be associated with a significantly lower (time) burden in most, but not all, measures considered. Transdermal treatment was significantly superior to oral treatment with regard to reduced administration time, ease of use, a lower rate of problems in administration, and a reduced burden in ADL. Some of these findings are in agreement with results from the IDEAL study [14-17, 30]. However, we go beyond these previous findings with regard to more detailed measures of burden, including a more detailed analysis of various measures of time burden (overall and for the application of the medication), as well as describing measures in five domains of caregiver burden that are rooted in caregivers' everyday 'care life'. We found significant reductions both of time needed for drug administration as well as time needed for associated administration problems, each of which is almost halved by the use of patches in comparison with capsules. While at a first glance a weekly reduction of almost 35 min per week seems to be negligible, it is important to point out that time represents a valuable resource, which is increasingly lacking in caregivers of patients with advancing dementia [31]. Thus, besides providing formal assistance to caregivers, and social and psychological support, simplifying the drug regimen additionally represents an important approach to reduce time burden and therefore to lower caregiver distress [32, 33].

Our findings with regard to mental health problems in the caregiver are less consistent. While we found elevated rates of major depression along with elevated scores for depressive symptoms for transdermally and orally treated patients, substantially increased rates of anxiety were markedly lower in caregivers of transdermally treated patients. It is not clear why we observed lower anxiety rates in the transdermal treatment group. We do not have an explanation of these differential effects but assume that the groups, although carefully matched, might have differed prior to treatment initiation. Another speculation with regard to the elevated depression scores might be that the commitment and involvement of caregivers in the treatment groups is higher than in the untreated group. This might be associated with an increased 'emotional burden', i.e. not only the mere objective burden of care has to be considered, but also the fact that in the majority of cases it was a close relative who was suffering from dementia, thus additionally contributing to the overall burden of care ('family effect') [34]. Such effects as well as effects of other caregivers involved from the family network were not considered in our data and might have confounded our results.

\section{Acknowledgements}

The IDEA study group wishes to thank all participating physicians, patients, and their caregivers for their efforts in this study. We also thank Bibiana Neumann for her assistance in the conduction of the field work. 


\section{Disclosure Statement}

O.R., A.E., H.F., and J.K. report no conflicts of interest. H.R. participated in advisory boards of Novartis, Eisai and Merz, and received honoraria for lectures from these companies. H.-U.W. received an unrestricted educational grant for the conduction of the IDEA study. R.D. has received honoraria from different pharmaceutical companies (Novartis, Boehringer Ingelheim, Pfizer, and Merz, among others) and participated in advisory boards of Baxter, Lilly, Affiris, and GE Healthcare. The IDEA study was supported by an unrestricted educational grant by Novartis Pharma GmbH (Nuremberg, Germany).

\section{References}

1 Birks J, Evans JG, Iakovidou V, Tsolaki M, Holt FE: Rivastigmine for Alzheimer's disease. Cochrane Database Syst Rev 2009;251.

-2 Bullock R, Dengiz A: Cognitive performance in patients with Alzheimer's disease receiving cholinesterase inhibitors for up to 5 years. Int J Clin Pract 2005;59:817-822.

-3 Grossberg G, Meng XY, Olin JT: Impact of rivastigmine patch and capsules on activities of daily living in Alzheimer's disease. Am J Alzheimers Dis Other Dement 2011;26:65-71.

-4 Mangialasche F, Solomon A, Winblad B, Merocci P, Kivipelto M: Alzheimer's disease: clinical trials and drug development. Lancet Neurol 2010;9:702-716.

-5 Mecocci P, Bladstrom A, Stender K: Effects of memantine on cognition in patients with moderate to severe Alzheimer's disease: post-hoc analyses of ADAS-COG and SIB total and single-item scores from six randomized, double-blind, placebo-controlled studies. Int J Geriatr Psychiatr 2009;24:532538.

-6 Brodaty H, Corey-Bloom J, Potocnik FC, Truyen L, Gold M, Damaraju CR: Galantamine prolongedrelease formulation in the treatment of mild to moderate Alzheimer's disease. Dement Geriatr Cogn Disord 2005;20:120-132.

-7 Erkinjuntti T, Kurz A, Gauthier S, Bullock R, Lilienfeld S, Damaraju CV: Efficacy of galantamine in probable vascular dementia and Alzheimer's disease combined with cerebrovascular disease: a randomised trial. Lancet 2002;359:1283-1290.

8 Rockwood K, Fay S, Song XW, MacKnight C, Gorman M: Attainment of treatment goals by people with Alzheimer's disease receiving galantamine: a randomized controlled trial. Can Med Assoc J 2006;174:1099-1105.

-9 Wimo A, Winblad B, Stoffler A, Wirth Y, Mobius HJ: Resource utilisation and cost analysis of memantine in patients with moderate to severe Alzheimer's disease. Pharmacoeconomics 2003;21:327340.

10 Chan ALF, Chien YW, Lin SJ: Transdermal delivery of treatment for Alzheimer's disease. Drugs Aging 2008;25:761-775.

-11 Oertel W, Ross JS, Eggert K, Adler G: Rationale for transdermal drug administration in Alzheimer disease. Neurology 2007;69:S4-S9.

-12 Emre M, Bernabei R, Blesa R, Bullock R, Cunha L, Daniels H, Dziadulewicz E, Forstl H, Froelich L, Gabryelewicz T, Levin O, Lindesay J, Martinez-Lage P, Monsch A, Tsolaki M, van Laar T: Drug profile: transdermal rivastigmine patch in the treatment of Alzheimer disease. CNS Neurosci Ther 2010; 16:246-253.

13 Grossberg GT, Sadowsky C, Olin JT: Rivastigmine transdermal system for the treatment of mild to moderate Alzheimer's disease. Int J Clin Pract 2010;64:651-660.

-14 Winblad B, Cummings J, Andreasen N, Grossberg G, Onofrj M, Sadowsky C, Zechner S, Nagel J, Lane R: A six-month double-blind, randomized, placebo-controlled study of a transdermal patch in Alzheimer's disease - rivastigmine patch versus capsule. Int J Geriatr Psychiatr 2007;22:456-467.

-15 Winblad B, Grossberg G, Frolich L, Farlow M, Zechner S, Nagel J, Lane R: A 6-month, double-blind, placebo-controlled study of the first skin patch for Alzheimer disease. Neurology 2007;69:S14-S22.

-16 Blesa R, Ballard C, Orgogozo J-M, Lane R, Thomas SK: Caregiver preference for rivastigmine patches versus capsules for the treatment of Alzheimer disease. Neurology 2007;69:S23-S28. 
-17 Winblad B, Kawata AK, Beusterien KM, Thomas SK, Wimo A, Lane R, Fillit H, Blesa R: Caregiver preference for rivastigmine patch relative to capsules for treatment of probable Alzheimer's disease. Int J Geriatr Psychiatr 2007;22:485-491.

$\checkmark 18$ Farlow MR, Alva G, Meng XM, Olin JT: A 25-week, open-label trial investigating rivastigmine transdermal patches with concomitant memantine in mild-to-moderate Alzheimer's disease: a post hoc analysis. Curr Med Res Opin 2010;26:263-269.

-19 McKhann G, Drachman D, Folstein M, Katzman R, Price D, Stadlan EM: Clinical diagnosis of Alzheimer's disease: report of the NINCDS-ADRA Work Group under the auspices of Department of Health and Human Services Task Force on Alzheimer's Disease. Neurology 1984;34:939-944.

-20 Folstein M, Folstein S, McHugh P: Mini-mental state: a practical method for grading the mental state of patients by the clinician. J Psychiatr Res 1975;12:189-198.

-21 Cummings J, Mega M, Gray K, Rosenberg-Thompson S, Carusi D, Gornbein J: The neuropsychiatric inventory: comprehensive assessment of psychopathology in dementia. Neurology 1994;44:23082314.

-22 Lawton MP, Brody EM: Assessment of older people: self-maintaining and instrumental activities of daily living. Gerontologist 1969;9:179-186.

-23 Mahoney F, Barthel D: Functional evaluation - the Barthel index. MD State Med J 1965;14:61-65.

24 Greiner W, Weijnen T, Nieuvenhuizen M, Oppe S, de Charro F: A European EQ-5D VAS valuation set; in Brooks R, Rabin R, de Charro F (eds): The Measurement and Valuation of Health Status Using EQ-5D - A European Perspective. Dortrecht, Kluwer, 2003, pp 103-142.

25 American Psychiatric Association: Diagnostic and Statistical Manual of Mental Disorders - Text Revision, ed 4. Washington, DC, American Psychiatric Association, 2000.

-26 Wittchen HU, Boyer P: Screening for anxiety disorders. Sensitivity and specificity of the anxiety screening questionnaire (ASQ-15). Brit J Psychiatry 1998;173:10-17.

27 Wittchen HU, Zaudig M, Fydrich T: SKID. Strukturiertes klinisches Interview für DSM-IV. Achse I und II. Handanweisung. Göttingen, Hogrefe, 1997.

-28 Royall RM: Model robust confidence intervals using maximum likelihood estimators. Int Stat Rev 1986;54:221-226.

-29 Arlt S, Hornung J, Eichenlaub M, Jahn H, Bullinger M, Petersen C: The patient with dementia, the caregiver and the doctor: cognition, depression and quality of life from three perspectives. Int J Geriatr Psychiatr 2008;23:604-610.

-30 Cummings JL, Ferris SH, Farlow MR, Olin JT, Meng XY: Effects of rivastigmine transdermal patch and capsule on aspects of clinical global impression of change in Alzheimer's disease: a retrospective analysis. Dement Geriatr Cogn Disord 2010;29:406-412.

-31 Georges J, Jansen S, Jackson J, Meyrieux A, Sadowska A, Selmes M: Alzheimer's disease in real life - the dementia carer's survey. Int J Geriatr Psychiatr 2008;23:546-551.

-32 Javadpour A, Ahmadzadeh L, Bahredar MJ: An educative support group for female family caregivers: impact on caregivers psychological distress and patient's neuropsychiatry symptoms. Int J Geriatr Psychiatr 2009;24:469-471.

- 33 Losada A, Pérez-Penaranda A, Rodriguez-Sanchez E, Gomez-Marcos MA, Ballesteros-Rios C, Ramos-Carrera IR, Campo-de la Torre MA, García-Ortiz L: Leisure and distress in caregivers for elderly patients. Arch Gerontol Geriatr 2010;50:347-350.

-34 Bobinac A, van Exel NJA, Rutten FFH, Brouwer WBF: Caring for and caring about: disentangling the caregiver effect and the family effect. J Health Econ 2010;29:549-556. 